\title{
A Dynamic Unit Cell Model for the All-Vanadium Flow Battery
}

\author{
A. A. Shah, ${ }^{\mathrm{z}}$ R. Tangirala, ${ }^{*}$ R. Singh, R. G. A. Wills, and F. C. Walsh"** \\ Electrochemical Engineering Laboratory, Energy Technology Research Group, School of Engineering Sciences, \\ University of Southampton, Highfield, Southampton SO171BJ, United Kingdom
}

In this paper, a mathematical model for the all-vanadium battery is presented and analytical solutions are derived. The model is based on the principles of mass and charge conservation, incorporating the major resistances, the electrochemical reactions and recirculation of the electrolyte through external reservoirs. Comparisons between the model results and experimental data show good agreement over practical ranges of the vanadium concentrations and the flow rate. The model is designed to provide accurate, rapid solutions at the unit-cell scale, which can be used for control and monitoring purposes. Crucially, the model relates the process time and process conditions to the state of charge via vanadium concentrations.

(C) 2011 The Electrochemical Society. [DOI: 10.1149/1.3561426] All rights reserved.

Manuscript submitted October 27, 2010; revised manuscript received February 5, 2011. Published April 7, 2011.

Electrochemical energy storage systems are crucial to the regulation and transmission of intermittent power derived from wind, solar and tidal sources. One promising example of such a storage system is the redox flow battery (RFB), which is suitable for both medium and large scales storage needs. ${ }^{1}$ Other important applications of RFB technology include power balancing and peak shaving for incumbent power generation methods. ${ }^{1-3}$

Examples of RFBs include the all-vanadium, vanadium/bromine, zinc-cerium and soluble-lead acid cells, of which the all-vanadium flow battery (VRFB) is the most developed. ${ }^{4-8}$ In 1985, Sum, Rychcik and Skyllas-Kazacos published the results of investigations into the direct application ${ }^{4,5}$ of the $\mathrm{V}^{2}+/ \mathrm{V}^{3}+$ and $\mathrm{VO}^{2}+/ \mathrm{VO}_{2}^{+}$redox couples to flow batteries. Subsequently, full patents for the allvanadium battery were filed in Australia and the USA (Ref. 8) with Unisearch Limited, University of New South Wales (UNSW) Australia as the applicant. The success of the VRFB is largely attributable to its high energy efficiencies (between 80 and $90 \%$ in large installations), the soluble state of the active species (no metal deposition), its potentially low cost per kilo watt hour for large storage capacities, the minimal gas evolution during normal operation, and use of the same element in both half-cells, avoiding problems associated with cross-contamination during long-term use. ${ }^{9}$

The main electrode reactions for the VFRB are as follows

$$
\begin{gathered}
\text { - ve electrode }: \mathrm{V}^{3+}+\mathrm{e}^{-} \underset{\text { discharge }}{\stackrel{\text { charge }}{\rightleftarrows}} \mathrm{V}^{2+} \\
E^{0}=-0.26 \mathrm{~V} \text { vs. SHE } \\
+ \text { ve electrode }: \mathrm{VO}^{2+}+\mathrm{H}_{2} \mathrm{O}-\mathrm{e}^{-} \underset{\text { discharge }}{\stackrel{\text { charge }}{\rightleftarrows}} \mathrm{VO}_{2}^{+}+2 \mathrm{H}^{+} \\
E^{0}=1.00 \mathrm{~V} \text { vs. SHE }
\end{gathered}
$$

with further side reactions (notably gas evolution) when the cells are overcharged. The electrolytes for each cell are circulated through the electrochemical cell and external reservoirs/tanks. The half cells are separated by an ion-selective membrane, typically Nafion, to transport protons. In theory, the energy storage capacity increases with the volume of the reservoirs and the concentrations of vanadium species, while the power output depends on the active electrode surface area and number of cells (when placed in a stack).

Laboratory-based investigations (considering materials, operating conditions, additives and cell structure) can be highly costly, as well as time- and labour-intensive. In order to reduce costs and timescales, modelling and simulation can be employed during the design and test cycles, and used to control and monitor systems in real time, ${ }^{10-13}$ provided of course that model parameters are avail-

\footnotetext{
* Electrochemical Society Student Member.

** Electrochemical Society Active Member.

z E-mail: A.Shah@soton.ac.uk
}

able from suitable experimental data. Mathematical models of the VRFB system have been developed by Shah et al. ${ }^{14-17}$ and by $\mathrm{Li}$ and Hikihara. ${ }^{18}$ These models incorporate the fundamental modes of transport, the electrochemical kinetics (including hydrogen and oxygen evolution ${ }^{16,17}$ ) and heat losses. ${ }^{15}$ It is not feasible, however, to incorporate this level of detail in control/monitoring tools or in stack models. There is, therefore, a need to develop control-oriented models ${ }^{19,20}$ that can rapidly, but accurately capture the performance of VRFB systems. In this paper, such a control-oriented model is developed for a unit-cell VRFB system. In the next section, experimental details are presented, followed by the model equations and analytical solutions in the Model Equation section. In the Result and Discussion section, the model is validated and the results of parametric studies are presented.

\section{Experimental}

A side view of the assembled cell is provided in Fig. 1. The body of the redox flow battery was constructed using polyvinyl chloride polymer outer plates (each $180 \times 180 \times 20 \mathrm{~mm}$ ). Copper end-plates $(150 \times 150 \times 3 \mathrm{~mm})$ were held in place using PTFE O-rings, and graphite foil $(150 \times 150 \times 2 \mathrm{~mm})$ was used to form a flexible interconnect between the copper plates and graphite plates $(150 \times 150 \times 5 \mathrm{~mm})$, placed on top of the graphite foil. PTFE gaskets $(150 \times 150 \times 3 \mathrm{~mm}$; active area of $100 \times 100 \mathrm{~mm})$ were positioned on top of the graphite plates. Carbon felt Sigratherm GFA5 electrodes $(100 \times 100 \times 4 \mathrm{~mm})$ were positioned within the gaskets. The effective volumetric porosity of the felt electrodes was $68 \pm 7$. The compartments were divided by a Nafion 115 cation exchange membrane $(150 \times 150 \mathrm{~mm}$; dry thickness ca. $125 \mu \mathrm{m})$. Electrolyte was circulated through each half-cell compartment through a glass reservoir (volume $250 \mathrm{ml}$, with a nitrogen gas atmosphere) and peristaltic pump circuit.

The electrolyte contained a total vanadium concentration in the range $1000-1600 \mathrm{~mol} \mathrm{~m}^{-3}$, as a $\mathrm{V}(\mathrm{III}) / \mathrm{V}(\mathrm{IV})$ mixture, in $4000 \mathrm{~mol}$ $\mathrm{m}^{-3} \mathrm{H}_{2} \mathrm{SO}_{4}$, at a temperature of $297 \pm 2 \mathrm{~K}$. The volumetric flow rate was in the range $1 \times 10^{-6}-3 \times 10^{-6} \mathrm{~m}^{3} \mathrm{~s}^{-1}\left(1-3 \mathrm{ml} \mathrm{s}^{-1}\right)$. An in-house personal computer and interface was used to monitor cell voltage. In addition, an open-circuit cell (divided by a Nafion 1135 cation exchange membrane) was used to monitor the cell potential difference between carbon rod electrodes ( $8 \mathrm{~mm}$ diameter). This cell provided a measure of the differential redox potential between the half-cell electrolytes leaving the cells, which was used as an indication of the open-circuit cell voltage (OCV) and, therefore, the state of charge (SoC). The cell current was also monitored. In the charge discharge experiments, the cell was charged at a constant current (typically in the range 2-10 A, corresponding to a current density of 200-1000 $\mathrm{A} \mathrm{m}^{-2}$ based on the projected area of each electrode) and discharged at the same constant current. The charge and discharge times were determined by the value of the opencircuit cell voltage as approximated by the potential difference 


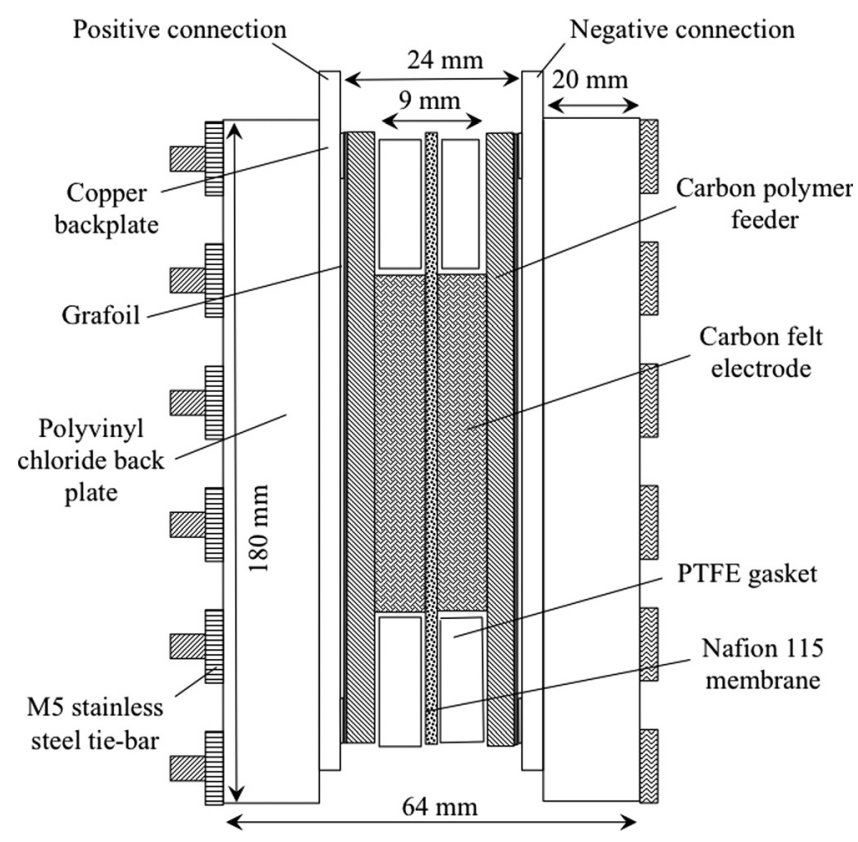

Figure 1. A side view of the assembled cell used in this study.

across the monitoring cell: $1.3 \mathrm{~V}$ at the end of each discharge and $1.5 \mathrm{~V}$ at the end of each charge. The cell was kept at open-circuit conditions for $2 \mathrm{~min}$ between each charge and discharge period. Typically, the charge and discharge parts of a cycle were each 30 $40 \mathrm{~min}$ in duration. The cell was cycled up to 30 times. All experiments exhibited excellent reproducibility of the cycles.

\section{Model Equations}

The electrochemical reactions included in the model are shown in Eqs. 1 and 2. Under normal operating conditions, oxygen and hydrogen evolution kinetics are not favoured in the all-vanadium system given the values of the standard potentials for Reactions 1 and 2. Furthermore, self discharge is neglected given the high charge and discharge currents considered.

Given an applied current density, $j_{\text {app}}$, the cell voltage (or cell potential difference), $E_{\text {cell }}$ is calculated from the following formula ${ }^{21}$

$$
\begin{aligned}
E_{\mathrm{cell}} & =E_{\mathrm{cell}}^{r e v}-\sum_{k}(I R)_{k}-\sum_{k}|\eta| \\
& =E_{\mathrm{cell}}^{r e v}-(I R)_{m}-(I R)_{e}-(I R)_{c}-\eta_{a}
\end{aligned}
$$

in which $E_{\text {cell }}^{\text {rev }}$ is the reversible OCV (since the outlet concentrations are used to calculate the OCV in the experimental monitoring cell, the state of charge definition is the same for both the model and experiments, though small differences exist between the true OCV and the OCV measured by the monitoring cell as discussed in the Simulation section), $\eta_{a}$ is the activation overpotential (with contributions from each electrode), $(I R)_{m}$ is the ohmic drop across the membrane, $(I R)_{e}$ is the ohmic drop associated with the electrolyte and $(I R)_{c}$ is the ohmic drop associated with the current collector. The OCV can be approximated using Nernst's equation (assuming unit activity coefficients) as follows ${ }^{21}$

$$
\begin{aligned}
E_{\text {cell }}^{\text {rev }} & =\left(E_{2}^{0}-E_{1}^{0}\right)+\frac{R T}{F} \ln \left(\frac{c_{\mathrm{V}(\mathrm{II})} c_{\mathrm{V}(\mathrm{V})}\left[\mathrm{H}^{+}\right]^{2}}{c_{\mathrm{V}(\mathrm{III})} c_{\mathrm{V}(\mathrm{IV})}}\right) \\
& =E^{0}+\frac{R T}{F} \ln \left(\frac{c_{\mathrm{V}(\mathrm{II})} c_{\mathrm{V}(\mathrm{V})}}{c_{\mathrm{V}(\mathrm{III})} c_{\mathrm{V}(\mathrm{IV})}}\right)+\frac{4.6 R T}{F} \log _{10}\left[\mathrm{H}^{+}\right]
\end{aligned}
$$

where: $E_{1}^{0}$ and $E_{2}^{0}$ (both functions of temperature) are the formal potentials for the reactions at the negative and positive electrodes,

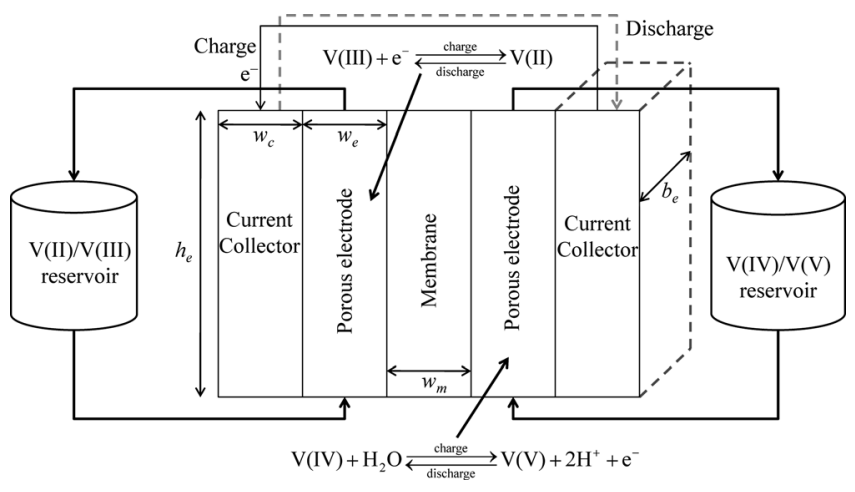

Figure 2. A schematic of the all vanadium redox flow battery and the components incorporated in the model.

respectively and $E^{0}=E_{2}^{0}-E_{1}^{0} ; R$ is the molar gas constant; $T$ is the cell temperature; $F$ is the Faraday constant; and $c_{i}$ is the molar concentration of (spatially distributed) species $i$. For very flow rates $\left(<1 \mathrm{ml} \mathrm{s}^{-1}\right)$, a high degree of stratification in the reactant concentrations would develop between the inlet and outlet to the cell. For the flow rates considered here, the stratification is expected to be low. The proton activity has been approximated by the concentration (in mol dm${ }^{-3}$ ) of protons, $\left[\mathrm{H}^{+}\right]$in the positive electrode. Note that the final term in Eq. 4 could be written in terms of the $p \mathrm{H}$ of the positive electrode solution, $p \mathrm{H}=-\log _{10}\left[\mathrm{H}^{+}\right]$. The formal potentials depend on temperature. ${ }^{22}$ The variations are, however, small and therefore neglected.

The ohmic losses associated with the current collector, membrane and the electrolyte can be modelled as follows

$$
(I R)_{c}=j_{\mathrm{appl}} \frac{w_{c}}{\sigma_{c}} ; \quad(I R)_{m}=j_{\mathrm{appl}} \frac{w_{m}}{\sigma_{m}} ; \quad(I R)_{e}=j_{\mathrm{appl}} \frac{w_{e}}{\varepsilon^{3 / 2} \sigma_{e}}
$$

respectively, where, $\sigma_{c}, \sigma_{m}$ and $\sigma_{e}$ are the conductivities and $w_{c}$, $w_{m}$ and $w_{e}$ are the widths of the current collector, membrane and the electrolyte, respectively, as shown in Fig. 2. Note that a Bruggeman correction has been used in the case of $(I R)_{e}$ to obtain the effective conductivity $\varepsilon^{3 / 2} \sigma_{e}$. For a Nafion membrane, the following empirical relationship can be employed ${ }^{23}$

$$
\sigma_{m}=(0.5139 \lambda-0.326) \exp \left(1268\left[\frac{1}{303}-\frac{1}{T}\right]\right)
$$

in $\mathrm{S} \mathrm{m}^{-1}$, where $\lambda$ is the membrane water content (moles of $\mathrm{H}_{2} \mathrm{O}$ to moles of $\mathrm{SO}_{3}^{-}$). Since the membrane is in constant contact with the liquid electrolyte on both sides, it is reasonable to assume that it is fully saturated; that is, ${ }^{24} \lambda=22$.

The overpotentials associated with the activation barrier to the electrode reactions can be calculated individually by inverting the Butler-Volmer equation (assuming equal charge transfer coefficients of 0.5 ) as follows ${ }^{21}$

$$
\begin{aligned}
& \text { - ve electrode (charge) }: \eta_{1}=-\frac{2 R T}{F} a \sinh \left(\frac{j_{\mathrm{app}}}{2 F k_{1} \sqrt{{ }^{c_{\mathrm{V}(\mathrm{III})}{ }^{c} \mathrm{~V}(\mathrm{II})}}}\right) \\
& + \text { ve electrode }(\text { charge }): \eta_{2}=\frac{2 R T}{F} a \sinh \left(\frac{j_{\mathrm{app}}}{2 F k_{2} \sqrt{{ }^{c_{\mathrm{V}(\mathrm{IV})}{ }^{C} \mathrm{~V}(\mathrm{~V})}}}\right)
\end{aligned}
$$

where $k_{1}$ and $k_{2}$ are the reaction rate constants associated with the reactions at the positive and negative electrodes, respectively (they can be related to the reference exchange current densities and reference reactant concentrations). The reaction constants are temperature dependent, and can be expressed as follows ${ }^{15}$ 
Table I. Default values for the electrochemical parameters and conductivities used in the model.

$$
\begin{aligned}
& \text { Symbol } \\
& E_{1}^{0} \\
& \begin{array}{l}
E_{2}^{0} \\
k_{1, \text { ref }}
\end{array} \\
& k_{2, r e f} \\
& \sigma_{c} \\
& \sigma_{e} \\
& { }^{\dagger} \text { Fitted parameter. } \\
& k_{1}=k_{1, r e f} \exp \left(-\frac{F E_{1}^{0}\left(T_{r e f}\right)}{R}\left[\frac{1}{T_{r e f}}-\frac{1}{T}\right]\right) \\
& k_{2}=k_{2, \text { ref }} \exp \left(\frac{F E_{2}^{0}\left(T_{\text {ref }}\right)}{R}\left[\frac{1}{T_{\text {ref }}}-\frac{1}{T}\right]\right)
\end{aligned}
$$

for known reference values, $k_{1, \text { ref }}$ and $k_{2 \text {,ref }}$ (given in Table I).

The recirculation of the electrolytes through reservoirs alters the concentrations of all species entering the electrodes. To model recirculation, the concentration of species $i$ in the appropriate reservoir, $c_{i}^{\text {res }}$ is introduced. The outlet/inlet area of the electrodes is given by $A_{\text {in }}=b_{e} w_{e}$, where $b_{e}$ and $w_{e}$ are the breadth and width of the electrode, respectively (see Fig. 2; default values are given in Table II). Assuming a constant liquid density, conservation of volume demands that the net change per unit time in the number of moles of species $i$ in the electrode due to recirculation is approximately equal to $\varepsilon A_{\text {in }} u\left(c_{i}^{\text {res }}-c_{i}\right)$, where $\varepsilon$ is the porosity of the electrode and $u$ is the electrolyte flow velocity (in $\mathrm{m} / \mathrm{s})$. Similarly, the net change in the reservoir concentration is approximately $-\varepsilon A_{\text {in }} u\left(c_{i}^{\text {res }}-c_{i}\right)$. Therefore, the mass balance of species $i$ in the reservoirs is

$$
\frac{d c_{i}^{r e s}}{d t}=-\frac{\varepsilon A_{\text {in }} u}{V_{r}}\left(c_{i}^{r e s}-c_{i}\right)=-\frac{\varepsilon \delta u}{h_{e}}\left(c_{i}^{r e s}-c_{i}\right)
$$

where $\varepsilon A_{\text {in }}$ is the actual area of the electrode, $h_{e}$ is the height of the electrode, $V_{e}=b_{e} w_{e} h_{e}$ is the volume of the electrode, $V_{r}$ is the volume of the reservoir and $\delta=V_{e} / V_{r}$ (see Table II for typical values). Note that the relationship $A_{i n}=V_{e} / h_{e}$ was used above.

The mass balance for species $i$ in the electrode incorporates recirculation and electrochemical reaction

$$
\begin{aligned}
\varepsilon V_{e} \frac{d c_{i}}{d t}=\varepsilon A_{\text {in }} u\left(c_{i}^{r e s}-c_{i}\right)-A_{s} \frac{j_{\text {app }}}{F} & i=\mathrm{V}(\mathrm{III}), \mathrm{V}(\mathrm{IV}) \\
\varepsilon V_{e} \frac{d c_{i}}{d t}=\varepsilon A_{\text {in }} u\left(c_{i}^{r e s}-c_{i}\right)+A_{s} \frac{j_{\text {app }}}{F} & i=\mathrm{V}(\mathrm{II}), \mathrm{V}(\mathrm{V})
\end{aligned}
$$

where $A_{s}$ is the active surface area for reaction, which can be written as $A_{s}=S V_{e}$, where $S$ is the specific surface area (per unit volume of the bulk electrode). Eliminating the recirculation terms in Eqs. 11 and 12 yields

$$
\frac{d}{d t}\left(\varepsilon \delta c_{i}+c_{i}^{r e s}\right)=-\frac{\delta S}{F} j_{\text {app }}
$$

which can be integrated, assuming a constant charge/discharge current, to give

$$
c_{i}^{r e s}=(\varepsilon \delta+1) c_{i}^{0}-\frac{\delta S}{F} j_{\text {app }} t-\varepsilon \delta c_{i} \quad i=\mathrm{V}(\mathrm{III}), \mathrm{V}(\mathrm{IV})
$$

subject to the initial conditions $c_{i}=c_{i}^{\text {res }}=c_{i}^{0}$. Equation 12 can now be recast as follows

$$
\frac{d c_{i}}{d t}+\tilde{\varepsilon} c_{i}=\tilde{\varepsilon} c_{i}^{0}-\frac{S j_{\mathrm{app}}}{\varepsilon F}\left(1+\frac{\varepsilon \delta}{\tau} t\right)
$$

in which

$$
\tau=\frac{h_{e}}{u} \text { and } \tilde{\varepsilon}=\frac{1}{\tau}(\varepsilon \delta+1)
$$

The ratio $\tau=h_{e} / u$ is a direct measure of the residence time for reaction. The solutions to Eq. 16, together with the initial conditions are

$$
c_{i}=c_{i}^{0}+\frac{S j_{\text {app }}}{\varepsilon \tilde{\varepsilon} F}\left(\frac{\varepsilon \delta+e^{-\tilde{\varepsilon} t}}{1+\varepsilon \delta}-1-\frac{\varepsilon \delta}{\tau} t\right) \quad i=\mathrm{V}(\mathrm{III}), \mathrm{V}(\mathrm{IV})
$$

A similar procedure for Eqs. 11 and 13 results in the solutions

$$
c_{i}^{r e s}=(\varepsilon \delta+1) c_{i}^{0}+\frac{\delta S}{F} j_{\text {app }} t-\varepsilon \delta c_{i} \quad i=\mathrm{V}(\mathrm{II}), \mathrm{V}(\mathrm{V})
$$

and

$$
c_{i}=c_{i}^{0}-\frac{S j_{\mathrm{app}}}{\varepsilon \tilde{\varepsilon} F}\left(\frac{\varepsilon \delta+e^{-\tilde{\varepsilon} t}}{1+\varepsilon \delta}-1-\frac{\varepsilon \delta}{\tau} t\right) \quad i=\mathrm{V}(\mathrm{II}), \mathrm{V}(\mathrm{V})
$$

To derive equations for the concentrations of water and protons, $c_{\mathrm{H}_{2} \mathrm{O}}$ and $c_{\mathrm{H}^{+}}$, respectively, electrochemical reaction (according to Eqs. 1 and 2), recirculation and osmotic drag through the membrane are considered. The molar flux of water through the membrane from the positive to negative electrode on charge can be approximated by $N_{\mathrm{H}_{2} \mathrm{O}}^{d r a g}=n_{d} j_{\text {app }} / F$, where $n_{d}$ is the so-called drag coefficient in the

Table II. Default values for the structural and geometric parameters used in the model.

\begin{tabular}{llc} 
Symbol & \multicolumn{1}{c}{ Description } & Value \\
\hline$w_{m}$ & Width of the membrane & $1.25 \times 10^{-4} \mathrm{~m}(125 \mu \mathrm{m})$ \\
$w_{e}$ & Width of the electrode & $0.004 \mathrm{~m}$ \\
$w_{c}$ & Width of the current collector & $0.005 \mathrm{~m}$ \\
$b_{e}$ & Breadth of the electrode & $0.1 \mathrm{~m}$ \\
$h_{e}$ & Height of the electrode & $0.1 \mathrm{~m}$ \\
$\varepsilon$ & Porosity of the electrode & 0.67 \\
$V_{r}$ & Volume of electrolyte in the reservoir & $2.232 \times 10^{-4} \mathrm{~m}^{3}$ \\
$S$ & Specific surface area for reaction & $420 \mathrm{~m}^{-1}$
\end{tabular}


empirical model of Springer et al. for water transport through Nafion. ${ }^{23}$ The water mass balances for each electrode are, therefore, as follows

$$
\begin{aligned}
\text {-ve electrode (charge) }: \varepsilon V_{e} \frac{d c_{\mathrm{H}_{2} \mathrm{O}}}{d t}= & \varepsilon A_{i n} u\left(c_{\mathrm{H}_{2} \mathrm{O}}^{\text {res }}-c_{\mathrm{H}_{2} \mathrm{O}}\right) \\
& +A_{e} n_{d} \frac{j_{\text {app }}}{F}
\end{aligned}
$$

$$
\text { +ve electrode(charge) } \begin{aligned}
\varepsilon V_{e} \frac{d c_{\mathrm{H}_{2} \mathrm{O}}}{d t}= & \varepsilon A_{i n} u\left(c_{\mathrm{H}_{2} \mathrm{O}}^{r e s}-c_{\mathrm{H}_{2} \mathrm{O}}\right) \\
& -\left(A_{e} n_{d}+A_{s}\right) \frac{j_{\text {app }}}{F}
\end{aligned}
$$

and the mass balances for the protons are

$$
\begin{aligned}
\text {-ve electrode (charge) }: \varepsilon V_{e} \frac{d c_{\mathrm{H}^{+}}}{d t}= & \varepsilon A_{\text {in }} u\left(c_{\mathrm{H}^{+}}^{r e s}-c_{\mathrm{H}^{+}}\right) \\
& +A_{e} \frac{j_{\text {app }}}{F}
\end{aligned}
$$

+ve electrode (charge) $: \varepsilon V_{e} \frac{d c_{\mathrm{H}^{+}}}{d t}=\varepsilon A_{\text {in }} u\left(c_{\mathrm{H}^{+}}^{\text {res }}-c_{\mathrm{H}^{+}}\right)$

$$
-\left(A_{e}-2 A_{s}\right) \frac{j_{\text {app }}}{F}
$$

The reservoir concentrations are given by (for both electrodes)

$$
\begin{aligned}
\frac{d c_{\mathrm{H}_{2} \mathrm{O}}^{r e s}}{d t} & =-\frac{\varepsilon \delta}{\tau}\left(c_{\mathrm{H}_{2} \mathrm{O}}^{r e s}-c_{\mathrm{H}_{2} \mathrm{O}}\right) \\
\frac{d c_{\mathrm{H}^{+}}^{r e s}}{d t} & =-\frac{\varepsilon \delta}{\tau}\left(c_{\mathrm{H}^{+}}^{r e s}-c_{\mathrm{H}^{+}}\right)
\end{aligned}
$$

Eliminating the recirculation terms in Eqs. 21/25 and Eqs. 22/25, followed by integration yields

$$
\begin{aligned}
c_{\mathrm{H}_{2} \mathrm{O}}^{r e s}= & (\varepsilon \delta+1) c_{\mathrm{H}_{2} \mathrm{O}}^{0}-\varepsilon \delta c_{\mathrm{H}_{2} \mathrm{O}} \\
& +\left\{\begin{array}{l}
-\frac{j_{\text {app }}}{F} \delta t\left(S+\frac{n_{d}}{w_{e}}\right)+\text { ve electrode } \\
\frac{n_{d}}{w_{e}} \frac{j_{\text {app }}}{F} \delta t
\end{array}\right.
\end{aligned}
$$

in which $c_{\mathrm{H}_{2} \mathrm{O}}^{0}=c_{\mathrm{H}_{2} \mathrm{O}}^{r e s}(0)=c_{\mathrm{H}_{2} \mathrm{O}}(0)$. Substituting Eq. 27 into Eqs. 21 and 22 and solving the resulting equations leads to

$$
\begin{aligned}
& c_{\mathrm{H}_{2} \mathrm{O}}=c_{\mathrm{H}_{2} \mathrm{O}}^{0}
\end{aligned}
$$

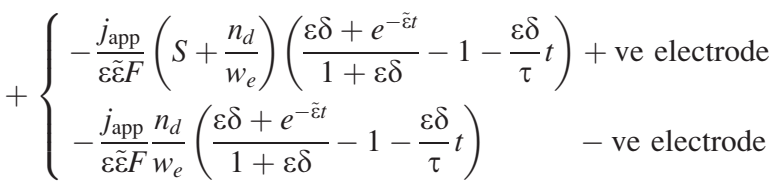

A similar procedure for the proton concentrations yields

$$
\begin{aligned}
c_{\mathrm{H}^{+}}^{r e s}= & (\varepsilon \delta+1) c_{\mathrm{H}^{+}}^{0}-\varepsilon \delta c_{\mathrm{H}^{+}} \\
& + \begin{cases}\frac{j_{\text {app }}}{F} \frac{\delta}{w_{e}} t\left(2 S w_{e}-1\right)+\text { ve electrode } \\
\frac{j_{\text {app }}}{F} \frac{\delta}{w_{e}} t & - \text { ve electrode }\end{cases}
\end{aligned}
$$

where $c_{\mathrm{H}^{+}}^{0}=c_{\mathrm{H}^{+}}^{r e s}(0)=c_{\mathrm{H}^{+}}(0)$, and

$$
\begin{aligned}
c_{\mathrm{H}^{+}}= & c_{\mathrm{H}^{+}}^{0} \\
& +\left\{\begin{array}{l}
\frac{j_{\text {app }}}{\varepsilon \tilde{\varepsilon} w_{e} F}\left(2 S w_{e}-1\right)\left(\frac{\varepsilon \delta+e^{-\tilde{\varepsilon} t}}{1+\varepsilon \delta}-1-\frac{\varepsilon \delta}{\tau} t\right)+\text { ve electrode } \\
\frac{j_{\text {app }}}{\varepsilon \tilde{\varepsilon} w_{e} F}\left(\frac{\varepsilon \delta+e^{-\tilde{\varepsilon} t}}{1+\varepsilon \delta}-1-\frac{\varepsilon \delta}{\tau} t\right)
\end{array}\right.
\end{aligned}
$$

\section{Results and Discussion}

General observations and formulae.-Before presenting the simulations, it is worthwhile making some general observations regarding the solutions derived above, in the context of a typical test cell. Formulae are derived to provide useful guidelines for the operation of VRFB cells under practical operating conditions.

In the realistic limit $\delta \rightarrow 0$, i.e., $V_{r} \gg V_{e}$, the term $S j_{\text {app }} /(\varepsilon \tilde{\varepsilon} F)$ in the solutions Eq. 18 for the $\mathrm{V}$ (II)/V(III) concentrations can be approximated by $h_{e} S j_{\text {app }} /(\varepsilon u F)$. The practical range for $u / h_{e}=1 / \tau$ in a test cell is $0.1-0.01$ (higher values can lead to leaking of the electrolyte and lower values to low charge efficiencies). Returning to Eq. 18, it can be seen that for $t \ll 1 / \tilde{\varepsilon}=O(\tau)$, the asymptotic form of the concentrations is given by $c_{i} \sim c_{i}^{0}-\frac{S j_{\text {app }}}{\varepsilon F} t\left(1-\frac{t}{2 \tau}\right)$ $(t \ll \tau)$

$$
c_{i} \sim c_{i}^{0}-\frac{S j_{\text {app }}}{\varepsilon F} t\left(1-\frac{t}{2 \tau}\right) \quad(t \ll \tau)
$$

For $t \gg \tau$, the exponential term in Eq. 18 can be disregarded and the asymptotic forms are

$$
c_{i} \sim c_{i}^{0}-S \frac{j_{\text {app }}}{\varepsilon F}\left(\tau+\varepsilon \delta t-2 \varepsilon \delta \tau-(\varepsilon \delta)^{2} t\right) \quad(t \gg \tau)
$$

Likewise, the proton concentration in the positive electrode (required below) can be approximated as

$$
\begin{aligned}
c_{\mathrm{H}^{+}} \sim & c_{\mathrm{H}^{+}}^{0}-\frac{j_{\text {app }}}{\varepsilon w_{e} F}\left(2 S w_{e}-1\right)\left(\tau+\varepsilon \delta t-2 \varepsilon \delta \tau-(\varepsilon \delta)^{2} t\right) \\
& \times(t \gg \tau)
\end{aligned}
$$

Thus, there are distinct stages in the charge cycle: an initial stage of $O(\tau)$ (about 1 min using the parameter values in Tables I-III) during which the electrode concentrations of V(II) and V(III) decrease at a linear rate $S j_{\text {app }} / \varepsilon F$ in $t$, followed by an intermediate stage with $t=O(\tau)$; in a final stage, defined by $t \gg \tau$ (the majority of the charge cycle), the rate of depletion reduces considerably to $\delta S j_{\text {app }} / \varepsilon F$, again linearly in $t$. During the intermediate stage, the variation in the concentrations is quadratic, as is seen by passing to the limit $t \rightarrow \tau$ in Eq. 31. For low initial concentrations or high currents, the first two stages will dominate by virtue of the short charge time. Such scenarios exist only under extreme conditions and are not representative of the experiments in this paper. The asymptotic behavior described above is verified later in this section (see Fig. 5).

To estimate the time taken to fully charge, $t_{f c}$, it is defined as the time taken to reach a zero concentration of the V(III) reactant in the negative electrode $\left(c_{\mathrm{V}(\mathrm{III})}=0\right)$ or of the $\mathrm{V}(\mathrm{IV})$ reactant in the positive electrode $\left(c_{\mathrm{V}(\mathrm{IV})}=0\right)$. Equation 18 show that these conditions are equivalent if the initial concentrations of V(IV) and V(III) are equal. Making the approximations $\delta \rightarrow 0$ and $e^{-\tilde{\varepsilon} t}=0$ in Eq. 18, for the reasons outlined above, the condition $c_{\mathrm{V}(\mathrm{III})}=0$ leads to

Table III. Default values for the operating parameters used in the model.

Symbol Description Value

$\begin{array}{lll}T & \text { Temperature } & 297 \mathrm{~K} \\ c_{\mathrm{V}(\mathrm{II})}^{0} & \text { Initial V(II) concentration } & 60 \mathrm{~mol} \mathrm{~m}^{-3} \\ c_{\mathrm{V}(\mathrm{III})}^{0} & \text { Initial V(III) concentration } & 1140 \mathrm{~mol} \mathrm{~m}^{-3} \\ c_{\mathrm{V}(\mathrm{IV})}^{0} & \text { Initial V(IV) concentation } & 1140 \mathrm{~mol} \mathrm{~m}^{-3} \\ c_{\mathrm{V}(\mathrm{V})}^{0} & \text { Initial V(V) concentration } & 60 \mathrm{~mol} \mathrm{~m}^{-3} \\ j_{\mathrm{app}} & \text { Current density } & 1000 \mathrm{~A} \mathrm{~m}^{-2} \\ c_{\mathrm{H}^{+}}^{0} & \text { Initial concentration of protons } & 4200 \mathrm{~mol} \mathrm{~m}^{-3} \\ c_{\mathrm{H}_{2} \mathrm{O}} & \text { Initial concentration of water } & 4.23 \times 10^{4} \mathrm{~mol} \mathrm{~m}^{-3} \\ \omega & \text { Linear flow rate of the electrolyte } & 1 \times 10^{-6} \mathrm{~m}^{3} \mathrm{~s}^{-1}\left(1 \mathrm{ml} \mathrm{s}^{-1}\right)\end{array}$




$$
t_{f c} \approx \frac{V_{r}}{V_{e}}\left(\frac{F c_{\mathrm{V}(\mathrm{III})}^{0}}{S j_{\mathrm{app}}}-\frac{h_{e} / u}{\varepsilon}\right)
$$

Equation 34 shows the charge time can be controlled by several means. It can be increased by increasing the reservoir volume, $V_{r}$ or decreasing the electrode volume, $V_{e}$, with all other parameters in Eq. 34 fixed in each case. It is interesting to note that while $t_{f c} \propto V_{r}$, it is inversely proportional to $V_{e}$. In the first case, the total vanadium content is increased and in the latter case the residence time for reaction is decreased, both of which lead to longer charge times (to an equivalent SoC). Alternatively, the initial concentration of vanadium, $c_{\mathrm{V}(\text { (III) }}^{0}$ can be increased or the volumetric current density, $S j_{\text {app }}$ decreased in order to increase $t_{f c}$. In the latter scenario, the available surface area for reaction or the bulk reaction rates are decreased. The ratio $h_{e} / u=\tau$, measuring the residence time for reaction, can also be used to control the charge time; clearly a decrease in $h_{e}$ or an increase in $u$, both of which will lead to a decrease in $\tau$, will increase $t_{f c}$.

The state of charge of the cell is a key parameter for ensuring the operation remains with a safe range, particularly with regard to gasevolving reactions. There are several methods for estimating the SoC of a battery, with one of the most common methods based on the open-circuit voltage (OCV). For certain ranges of the SoC, the relationship between the OCV and SoC can be approximated as linear: SoC $=\alpha_{1}+\alpha_{2} \mathrm{OCV}$, for constants $\alpha_{1}$ and $\alpha_{2}$ that are determined by the OCV values at full and zero capacity. ${ }^{25}$ These extreme values of the OCV, which can be measured, are denoted $E_{\max }$ and $E_{\text {min }}$, corresponding respectively to $\mathrm{SoC}=1$ and $\mathrm{SoC}=0$. Inserting these values into the expression for SoC gives $\alpha_{1}=-E_{\min } /\left(E_{\max }\right.$ $\left.-E_{\min }\right)$ and $\alpha_{2}=1 /\left(E_{\max }-E_{\min }\right)$. Subsequently inserting these expression and Eqs. 18 and 20 into Eq. 4 for the OCV leads to (converting the proton concentration to $\mathrm{mol} \mathrm{dm}^{-3}$ )

$$
\begin{aligned}
\operatorname{SoC}(t)= & -\frac{E_{\min }}{E_{\max }-E_{\min }}+\frac{E^{0}}{E_{\max }-E_{\min }}+\frac{2 R T}{F\left(E_{\max }-E_{\min }\right)} \\
& \times \ln \left(\frac{c_{\mathrm{V}(\mathrm{III})}^{0}+\xi(t)}{c_{\mathrm{V}(\mathrm{II})}^{0}-\xi(t)}\right)+\frac{4.6 R T}{F\left(E_{\max }-E_{\min }\right)} \\
& \times\left\{\log _{10}\left(c_{\mathrm{H}^{+}}^{0}+\left[\frac{2 S w_{e}-1}{S w_{e}}\right] \xi(t)\right)-3\right\}
\end{aligned}
$$

since $c_{\mathrm{V}(\mathrm{IV})}^{0}=c_{\mathrm{V}(\mathrm{III})}^{0}$ and $c_{\mathrm{V}(\mathrm{II})}^{0}=c_{\mathrm{V}(\mathrm{V})}^{0}$ [that last term includes the factor of $10^{-3}$ that is introduced when converting $c_{\mathrm{H}^{+}}$to units of mol $\mathrm{dm}^{-3}$, noting that $\log _{10}\left(10^{-3}\right)=-3$ ]. The function $\xi(t)$ is given by $\xi(t)=\frac{S j_{\text {app }}}{\varepsilon \tilde{\varepsilon} F}\left(\frac{\varepsilon \delta+e^{-\bar{\varepsilon} t}}{1+\varepsilon \delta}-1-\frac{\varepsilon \delta}{\tau} t\right)$

$$
\xi(t)=\frac{S j_{\mathrm{app}}}{\varepsilon \tilde{\varepsilon} F}\left(\frac{\varepsilon \delta+e^{-\tilde{\varepsilon} t}}{1+\varepsilon \delta}-1-\frac{\varepsilon \delta}{\tau} t\right)
$$

For $\delta \ll 1$ and $t \gg \tau$, Eq. 35 can be simplified to

$$
\begin{aligned}
\operatorname{SoC}(t) \sim & -\frac{E_{\min }}{E_{\max }-E_{\min }}+\frac{E^{0}}{E_{\max }-E_{\min }}+\frac{2 R T}{F\left(E_{\max }-E_{\min }\right)} \\
& \times \ln \left(\frac{c_{\mathrm{V}(\mathrm{III})}^{0}-\varsigma(t)}{c_{\mathrm{V}(\mathrm{II})}^{0}+\varsigma(t)}\right)+\frac{4.6 R T}{F\left(E_{\max }-E_{\min }\right)} \\
& \times\left\{\log _{10}\left(c_{\mathrm{H}^{+}}^{0}-\left[\frac{2 S w_{e}-1}{S w_{e}}\right] \varsigma(t)\right)-3\right\}
\end{aligned}
$$

since $c_{\mathrm{V} \text { (V) }}=c_{\mathrm{V}(\mathrm{II})} \sim c_{\mathrm{V}(\mathrm{II})}^{0}+S j_{\mathrm{app}}(\tau+\varepsilon \delta t) / F$ for $t \gg \tau$. In Eq. 37, $\varsigma(t)$ is given by

$$
\varsigma(t)=\frac{S j_{\text {app }}}{\varepsilon F}\left(\tau+\varepsilon \delta t-2 \varepsilon \delta \tau-(\varepsilon \delta)^{2} t\right)
$$

Equation 37, which is a function only of time, is valid for the majority of a typical charge cycle. It provides a convenient first-order approximation to the SoC under practical conditions. Alternatively, the more complex, but still relatively straightforward expression Eq. 35 can be used.

Simulations.- The charge/discharge curves for the experiments described in the Experimental section were simulated using the analytical solutions derived above. The default parameters are given in Tables I-III. The initial concentrations of the vanadium species (Table III), i.e. at the beginning of charge, were such that a $5 \%$ of the total vanadium concentration was considered to be in the V(II) state in the negative electrode and in the $\mathrm{V}(\mathrm{V})$ state in the positive electrode. Equation 4 was used to control the charge and discharge time; as in the experiment, the OCV with respect to the cell reactant concentrations was cycled between $1.3 \mathrm{~V}$ (beginning of charge/end of discharge) and $1.5 \mathrm{~V}$ (end of charge). The total initial concentrations were estimated from the experimental conditions, along with the assumption that sulphuric acid dissociates completely in water (based on the value of the dissociation constant). In the discussion below, the electrolyte flow rate, $\omega$ is specified rather than the velocity. The conversion is given by $\omega=\varepsilon u A_{i n}$.

As with all models, it was necessary to fit certain parameters in order to match the experimental results. The fitting parameters (kept to a minimum) were (i) the specific surface area $S$, (ii) the electrolyte conductivities $\sigma_{e}$, and the rate constant $k_{1, r e f}$, given in Eq. 9 . The first of these parameters is very difficult to determine and the estimates can vary by orders of magnitude. The electrolyte conductivites for the particular system were not known, so were used as free parameters for fitting purposes. For simplicity, the values were set equal for both half cells. The final fitting parameter is also unknown for the present system. The fitted value is, however, consistent with previous reports. ${ }^{14-17} \mathrm{We}$ point out that the fitting of parameters was performed only once, using the base-case parameter values in Tables I-III.

Figure 3 shows the result of simulations at two different concentrations of vanadium, with other parameters as in Table I. A comparison to experimental data is also provided. The analytical solutions capture the charge-discharge behaviour well, particularly with respect to the trends observed. The best fit over all parameter variations (see also Fig. 4) could not eliminate all quantitative discrepancies, although theses discrepancies are relatively small. The model does not consider gas evolving reactions and self discharge, which lower the charge efficiency in the real case. Furthermore, as seen in

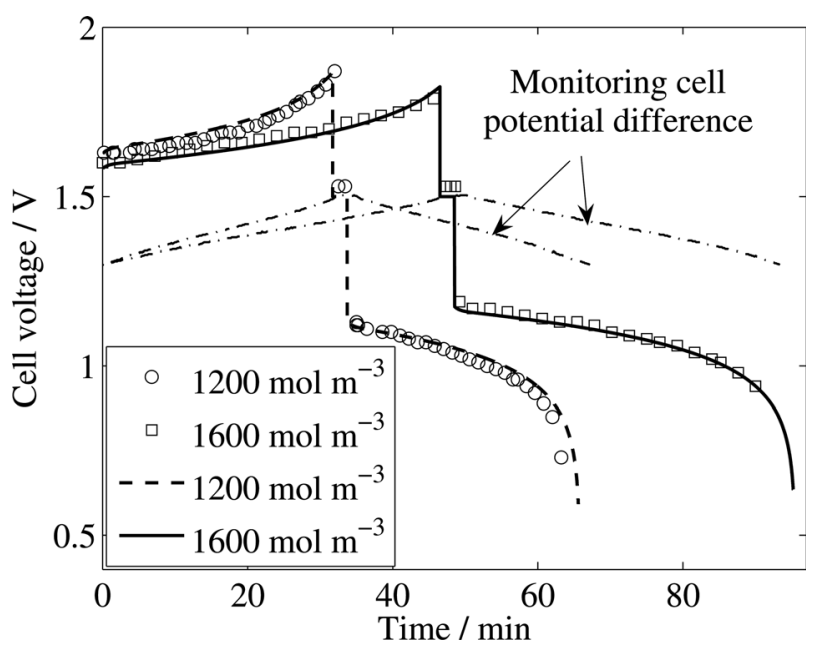

Figure 3. Comparison between experimental and analytical charge/discharge curves at two different vanadium concentrations. The open symbols represent he experimental data while the curves represent the simulations. In all cases the temperature was $300 \mathrm{~K}$, the flow rate was $1 \times 10^{-6} \mathrm{~m}^{3} \mathrm{~s}^{-1}$ $\left(1 \mathrm{ml} \mathrm{s}^{-1}\right)$ and the current density was $1000 \mathrm{~A} \mathrm{~m}^{-2}$. 

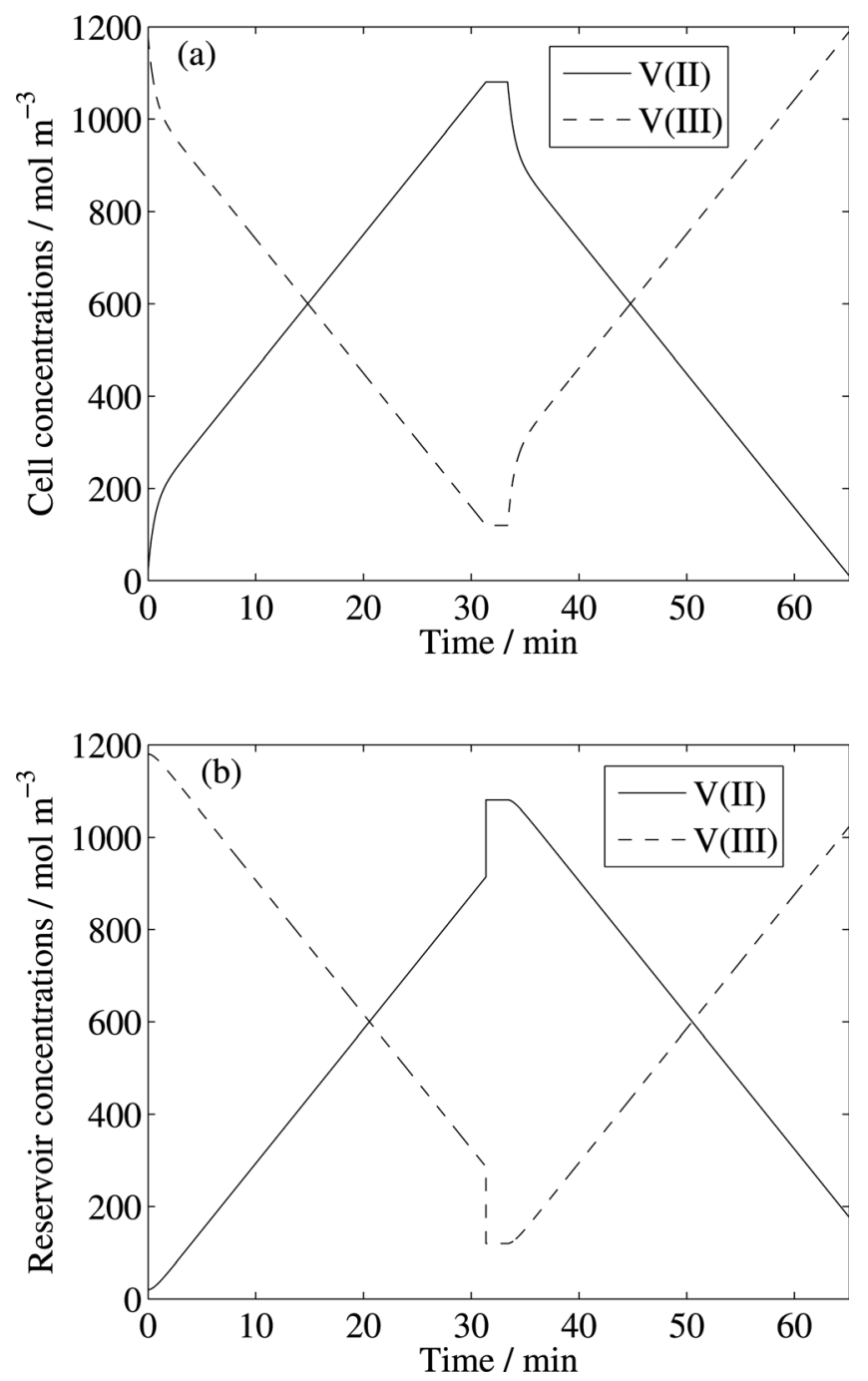

Figure 4. Evolutions of the analytical V(II) and V(III) species concentrations in (a) the negative electrode and (b) the negative-electrolyte reservoir during the full charge-discharge cycle. The cell temperature was $300 \mathrm{~K}$, the vanadium concentration was $1200 \mathrm{~mol} \mathrm{~m}^{-3}$, the flow rate was $1 \times 10^{-6} \mathrm{~m}^{3}$ $\mathrm{s}^{-1}\left(1 \mathrm{ml} \mathrm{s}^{-1}\right)$ and the current density was $1000 \mathrm{~A} \mathrm{~m}^{-2}$ (corresponding to the dashed curve in Fig. 3).

Fig. 3, there is a small discrepancy of approximately $0.03 \mathrm{~V}$ between the potential difference across the monitoring cell and the true OCV $(\approx 1.53 \mathrm{~V})$ in both cases. The model charge time is controlled by the attainment of an OCV of $1.5 \mathrm{~V}$, which leads to the small discrepancy between the model and experimental cell-voltage curves at open-circuit conditions.

Evolutions of the analytical V(II) and V(III) species concentrations in the negative electrode and negative-electrolyte reservoir during a full charge-discharge cycle are shown in Fig. 4. These are based on Eqs. 15, 18, 19, and 20. The cell temperature was $300 \mathrm{~K}$, the vanadium concentration was $1200 \mathrm{~mol} \mathrm{~m}^{-3}$, the flow rate was $1 \times 10^{-6} \mathrm{~m}^{3} \mathrm{~s}^{-1}\left(1 \mathrm{ml} \mathrm{s}^{-1}\right)$ and the current density was $1000 \mathrm{~A}$ $\mathrm{m}^{-2}$. The rate of depletion of V(III) [accumulation of $\mathrm{V}(\mathrm{II})$ ] in the cell during charge is greater than the rate of V(III) depletion [V(II) accumulation] in the reservoir. This would be expected since the electrolyte volume in the reservoir and, therefore, V(III) content is much higher. Both profiles show a linear rate of decline, which is again due to the much greater volume of the reservoir compared to the cell volume.

A comparison of the full analytical solution for the V(III) concentration (Eq. 18) and the asymptotic solutions given by Eqs. 31 and 32 is provided in Fig. 5 for the case depicted in Fig. 4. The time

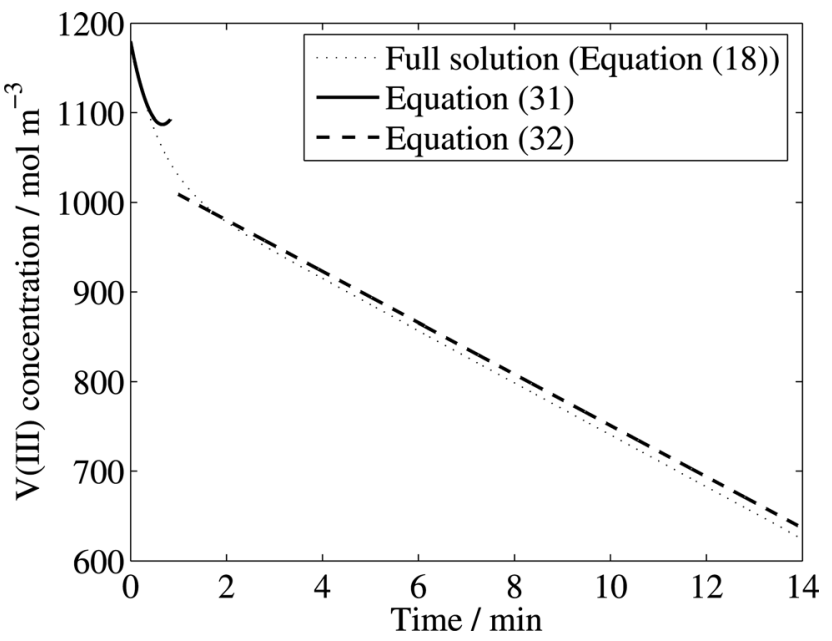

Figure 5. A comparison of the full analytical solution for the V(III) species concentration (Eq. 18) and the asymptotic solutions given by Eqs. 31 and 32 The cell temperature was $300 \mathrm{~K}$, the vanadium concentration was $1200 \mathrm{~mol}$ $\mathrm{m}^{-3}$, the flow rate was $1 \times 10^{-6} \mathrm{~m}^{3} \mathrm{~s}^{-1}\left(1 \mathrm{ml} \mathrm{s}^{-1}\right)$ and the current density was $1000 \mathrm{~A} \mathrm{~m}^{-2}$.

is truncated at 14 min of charging in order that a clear comparison can be made. The asymptotic solutions predict the full solution accurately. The full solutions also exhibit the three-stage process described in the above section, with Eqs. 31 and 32 capturing the first and last of the stages.

The effects of variations in the flow rate $\omega$ can be seen in Fig. 6 . In both simulations, each electrode/reservoir possessed a total vanadium concentration of $1200 \mathrm{~mol} \mathrm{~m} \mathrm{~m}^{-3}$. Experimental chargedischarge curves are provided for comparison. The simulated and experimental curves are again in good agreement, with a longer charge time and higher terminal cell voltage on charge (to the equivalent SoC) for the higher flow rate of $2 \times 10^{-6} \mathrm{~m}^{3} \mathrm{~s}^{-1}\left(2 \mathrm{ml} \mathrm{s}^{-1}\right)$. The longer charge time is a direct result of the decreased residence time for reaction, as discussed in the previous section.

The final result is depicted in Fig. 7, which shows simulated charge/discharge curves for three system temperatures. In all cases the vanadium concentration was $1200 \mathrm{~mol} \mathrm{~m}^{-3}$, the flow rate was $1 \times 10^{-6} \mathrm{~m}^{3} \mathrm{~s}^{-1}\left(1 \mathrm{ml} \mathrm{s}^{-1}\right)$ and the current density was $1000 \mathrm{~A} \mathrm{~m}^{-2}$. The deviation of the cell voltage from the equilibrium value decreases as the temperature is increased. The capacity of the battery (proportional to time since the discharge current is constant) increases mildly

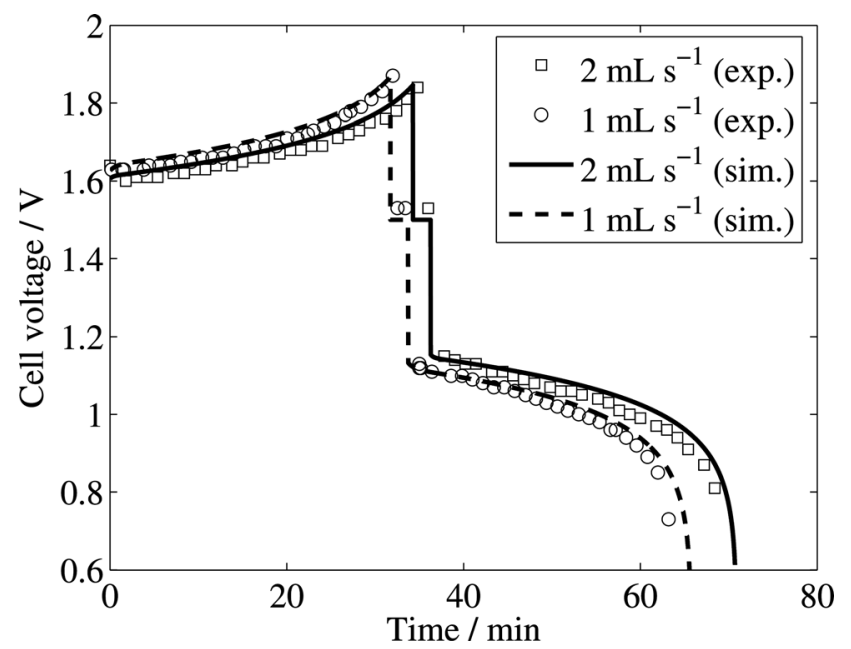

Figure 6. Comparison between experimental and analytical charge/discharge curves at two different volumetric electrolyte flow rates. In all cases the temperature was $297 \mathrm{~K}$, the vanadium concentration was $1200 \mathrm{~mol} \mathrm{~m}^{-3}$ and the current density was $1000 \mathrm{~A} \mathrm{~m}^{-2}$. 


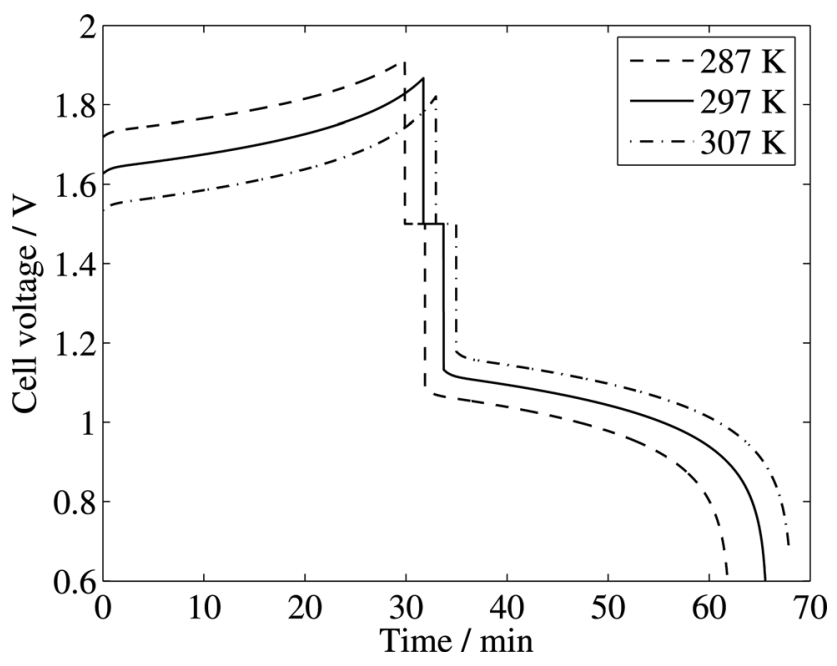

Figure 7. Simulated charge/discharge curves for a range of system temperatures. In all cases the vanadium concentration was $1200 \mathrm{~mol} \mathrm{~m}^{-3}$, the flow rate was $1 \times 10^{-6} \mathrm{~m}^{3} \mathrm{~s}^{-1}\left(1 \mathrm{ml} \mathrm{s}^{-1}\right)$ and the current density was $1000 \mathrm{~A} \mathrm{~m}^{-2}$.

with increased temperature. An increased temperature increases the rate constants (9) and (10), which leads to decreases in the magnitudes of the overpotentials (7) and (8); note that these decreases dominate any increases due to the algebraic factor. Moreover, the membrane conductivity, which is given by Eq. 6, increases exponentially with temperature. Therefore, as the temperature is increased, the ohmic loss across the membrane decreases, which in turn decreases the deviation from the OCV.

\section{Conclusions}

The development of practical modelling tools for redox flow batteries is an important consideration for the design, control and monitoring of these systems. In this paper, a control-oriented model for the all-vanadium flow battery has been developed, based on the major components of voltage loss and taking into account the electrode kinetics and recirculation of the half-cell electrolytes. The model is able to relate important characteristics of performance (such as the time to charge/discharge and the state of charge) to key system properties. Simulations have demonstrated that the model is able to capture the performance in practical systems to a high degree of accuracy.
The model developed can readily be extended to other vanadium RFBs (e.g., vanadium-bromide). It can also be used as the basis for a stack model of these systems. In a forthcoming paper, the present model is extended to included temperature effects and coupling between cells arranged in parallel and series, with further validation against experimental data.

\section{Acknowledgments}

The authors would like to acknowledge funding from the Technology Strategy Board, UK, and partnership with Re-Fuel Ltd and Scottish Power, from which the present work has benefited.

University of Southampton assisted in meeting the publication costs of this article.

\section{References}

1. I. Tsuda, K. Nozaki, K. Sakuta, and K. Kurokawa, Sol. Energy Mater. Sol. Cells, 47, 101 (1997).

2. C. Ponce de León, A Frías-Ferrer, J. González-García, D. A. Szánto, and F. C. Walsh, J. Power Sources, 160, 716 (2006).

3. F. C. Walsh, Pure Appl. Chem., 73, 1819 (2001).

4. E. Sum, M. Rychcik, and M. Skyllas-Kazacos, J. Power Sources, 16, 85 (1985).

5. E. Sum and M. Skyllas-Kazacos, J. Power Sources, 15, 179 (1985).

6. M. Skyllas-Kazacos and F. Grossmith, J. Electrochem. Soc., 134, 2950 (1987).

7. M. Skyllas-Kazacos, M. Rychcik, R. G. Robins, A. G. Fane, and M. Green, J. Electrochem. Soc., 133, 1057 (1986).

8. M. Skyllas-Kazacos, M. Rychick, and R. Robins, U.S. Pat. 4786567 (1988).

9. M. J. Watt-Smith, R. G. A. Wills, and F. C. Walsh, Encyclopedia of Electrochemical Power Sources, Amsterdam, The Netherlands (2009).

10. A. A. Shah and F. C. Walsh, J. Power Sources, 185, 287 (2008).

11. A. A. Shah, T. R. Ralph, and F. C. Walsh, J. Electrochem Soc., 156, B465 (2009).

12. C. Y. Wang, W. B. Gu, and B. Y. Liaw, J. Electrochem. Soc., 145, 3407 (1998).

13. T. I. Evans, T. V. Nguyen, and R. E. White, J. Electrochem. Soc., 136, 328 (1989).

14. A. A. Shah, M. J. Watt-Smith, and F. C. Walsh, Electrochim. Acta, 53, 8087 (2008).

15. H. Al-Fetlawi, A. A. Shah, and F. C. Walsh, Electrochim. Acta, 55, 78 (2009).

16. A. A. Shah, H. Al-Fetlawi, and F. C. Walsh, Electrochim. Acta, 55, 1125 (2010).

17. H. Al-Fetlawi, A. A. Shah, and F. C. Walsh, Electrochim. Acta, 55, 3192 (2010).

18. M. Li and T. Hikihara, IEICE Trans. Fundamentals, E91-A, 1741 (2008).

19. D. P. Scamman, G. W. Reade, and E. P. L. Roberts, J. Power Sources, 189, 1220 (2009).

20. D. P. Scamman, G. W. Reade, and E. P. L. Roberts, J. Power Sources, 189, 1231 (2009).

21. J. Newman, Electrochemical Systems, Prentice Hall, Englewood Cliffs, NJ (1991).

22. S. G. Bratsch, J. Phys. Chem. Ref. Data, 18, 1 (1989).

23. T. Springer, T. Zawodzinski, and S. Gottesfeld, J. Electrochem. Soc., 138, 2334 (1991).

24. T. A. Zawodzinski, C. Derouin, S. Radzinski, R. J. Sherman, V. T. Smith, T. E. Springer, and S. Gottesfeld, J Electrochem. Soc., 140, 1041 (1993).

25. Handbook of Batteries, 3rd ed., D. Linden and T. B. Reddy, Editors, McGraw-Hill, New York (2002).

26. M. Gattrell, J. Park, B. MacDougall, J. Apte, S. McCarthy, and C. W. Wu, J. Electrochem. Soc., 151, 123 (2004). 